\title{
Atovaquone-proguanil in the treatment of imported uncomplicated Plasmodium falciparum malaria: a prospective observational study of 553
} cases

Hugues Cordel ${ }^{1,2}$, Johann Cailhol ${ }^{1,2}$, Sophie Matheron ${ }^{3}$, Martine Bloch $^{4}$, Nadine Godineau ${ }^{5}$, Paul-Henri Consigny ${ }^{6}$, Hélène Gros ${ }^{7}$, Pauline Campa ${ }^{8}$, Patrice Bourée ${ }^{9}$, Olivier Fain ${ }^{10}$, Pascal Ralaimazava ${ }^{1}$ and Olivier Bouchaud ${ }^{1,2^{*}}$

\begin{abstract}
Background: Each year, thousands of cases of uncomplicated malaria are imported into Europe by travellers. Atovaquone-proguanil (AP) has been one of the first-line regimens used in France for uncomplicated malaria for almost ten years. While AP's efficacy and tolerance were evaluated in several trials, its use in "real life" conditions has never been described. This study aimed to describe outcome and tolerance after AP treatment in a large cohort of travellers returning from endemic areas.

Methods: Between September 2002 and January 2007, uncomplicated malaria treated in nine French travel clinics with AP were followed for 30 days after AP initiation. Clinical and biological data were collected at admission and during the follow-up.

Results: A total of 553 patients were included. Eighty-eight percent of them were born in Africa, and 61.8\% were infected in West Africa, whereas $0.5 \%$ were infected in Asia. Migrants visiting friends and relatives (VFR) constituted $77.9 \%$ of the patients, the remainder (32.1\%) were backpackers. Three-hundred and sixty-four patients (66\%) fulfilled follow-up at day 7 and 265 (48\%) completed the study at day 30. Three patients had treatment failure. One-hundred and seventy-seven adverse drug reactions (ADR) were reported during the follow-up; $115(77 \%)$ of them were digestive ADR. Backpackers were more likely to experiment digestive ADR compared to VFR (OR = 3.8; Cl 95\% [1.8-8.2]). Twenty patients had to be switched to another regimen due to $A D R$.

Conclusion: This study seems to be the largest in terms of number of imported uncomplicated malaria cases treated by AP. The high rate of reported digestive ADR is striking and should be taken into account in the follow-up of patients since it could affect their adherence to the treatment. Beside AP, artemisinin combination therapy (ACT) is now recommended as first-line regimen. A comparison of $A P$ and $A C T$, in terms of efficacy and tolerance, would be useful.
\end{abstract}

Keywords: Atovaquone-proguanil, Imported, Uncomplicated, Malaria, Tolerance

\section{Background}

In 2010, the World Health Organization (WHO) estimated that 216 million cases of malaria occurred and were responsible of 650,000 deaths [1]. More and more people travel from northern countries to malaria-endemic areas. As a result, imported malaria is not exceptional in Europe,

\footnotetext{
* Correspondence: olivier.bouchaud@avc.aphp.fr

'Department of Infectious and Tropical Diseases, Hôpital Avicenne, Assistance Publique-Hôpitaux de Paris, Bobigny, France

2LEPS EA3412, Université Paris 13 - Sorbonne Paris Cité, Paris, France

Full list of author information is available at the end of the article
}

where approximately 7,000 cases were notified in 2010 to the WHO Regional Office for Europe [2]. The actual case numbers might be higher, due to under-notification. With its historical links with West and Central Africa, France is the leading European country in terms of cases of malaria diagnosed with 3,560 cases reported in 2011 by the National Malaria Reference Centre [3]. In Europe and other northern countries, travellers are treated by highly effective anti-malarial therapy, by contrast to malaria-endemic countries where appropriate treatments are not always available. A recent publication has shown that 18 different regimens

\section{Ciomed Central}


were used in Europe, with the most prescribed being the fixed combination, atovaquone-proguanil (AP), commercially known as Malarone [4].

AP has been licensed in France since 1997 and marketed since late 2001 and it remains the principal treatment of acute malaria. Since the National Experts Committee recommended in 2007 that AP, together with artemetherlumefantrine, be used as first-line regimen, 'old drugs' such as quinine or mefloquine were downgraded to second-line treatment [5]. Atovaquone belongs to the family of hydroxy-naphthoquinones, which anti-malarial activity was first described 40 years ago [6,7]. Its mode of action is original, blocking the electron transport chain of the parasite's mitochondria [8]. Used on its own, atovaquone has limited value, as shown by a significant relapse rate [9]. Its association with proguanil has shown excellent efficacy on acute malaria in numerous clinical trials, due to a synergistic effect [10-17]. AP is also widely used as an efficient and well-tolerated chemoprophylaxis for travellers.

Efficacy and tolerance of AP were extensively reported from clinical trials performed in malaria-endemic areas [10-14]. However, these results might not be valid in the case of imported malaria, due to epidemiological and biological differences (i e, study conditions, immune status, parasitaemia, heterogeneity of parasite strains, perception of side effects). Most of the studies comparing AP to other drugs were performed in endemic countries, and few observational or retrospective studies from non endemic countries have been published, amongst which only was a comparative trial, yet with a limited number of subjects has been published [18-24]. A recent international, prospective, observational study analysed a large cohort (504 cases) of imported Plasmodium falciparum malaria cases. It provided interesting data on the use of AP with a relatively large series $(n=253)$, but heterogeneity of practices, due to 'centre effects' between participating European centres may limit the interpretation of the study [4].

The aim of this study was to bridge this gap in knowledge by providing data on the use of AP in 'real life' conditions in France, using a large series of uncomplicated imported cases of $P$. falciparum.

\section{Methods}

\section{Study design}

A multicentre, prospective, observational study was set up in nine travel clinics located in Paris and its suburbs, between September 2002 and January 2007. Written informed consent was obtained from each participating subject (from accompanying parents for children less than 18 years old) and data management procedures were approved by the French Commission National de l'Informatique et des Libertés (CNIL).

\section{Study population}

Recruitment criteria were as following: more than 12 years old (minimal age for prescribing the standard dosage of AP according to manufacturer recommendations); an acute malaria onset due to $P$. falciparum, acquired in an endemic country and imported to France; onset treated with AP; and, having signed an informed consent. Mixed infections, defined by an infection to P. falciparum combined with another species of Plasmodium were also included. Diagnosis of malaria was based on positive Giemsa-stained thin and thick blood smears tests performed by the parasitology laboratory in each participating centre. All patients had to tolerate oral therapy when they were included in the study. Patients were excluded if: they fulfilled any of the clinical and biological WHO criteria of severe or complicated malaria [25], particularly parasitaemia higher than $4 \%$ even for immune patients; if they had a history of allergy to AP; if pregnant or breast-feeding. Hospitalization of patients was not required if the clinical status was sufficiently good and if compliance to the treatment and follow-up was foreseen as acceptable. Patients initially treated with less than three days of intravenous quinine because of vomiting at admission were not excluded as tolerance data in that particular situation were of interest. Decision for choosing AP or another anti-malarial drug was the responsibility of each investigator. Data were collected via a standardized datasheet and analysed only for patients treated with AP.

\section{Procedures/data collection}

Initial evaluation included individual characteristics (date of birth, sex, country of birth, country of residence), details on travels in malaria-endemic areas (date of arrival in France, countries visited and duration of travels), type of malaria prophylaxis, medical history (co-morbidities and previous malaria onsets) and details on actual onset. A semi-immune person was defined as a patient who declared a history of malaria. Clinical examination was followed by: blood smear; laboratory test exploring liver, kidney, haematological and metabolism functions; and, an electrocardiogram. According to international and French follow-up guidelines, patients were monitored at day 3, day 7 and one month (day 28 to 30) after AP initiation with clinical examination, blood smear and haematological, liver and kidney functions. Doses for AP and all anti-malarial drugs, except mefloquine, is one tablet daily for chemoprophylaxis. Compliance to daily chemoprophylaxis during the travel period was evaluated during the initial interview: a good compliance was defined by one or less missed dose by week during the travel period and one month after return. For mefloquine (MQ), compliance was defined by one or less missed dose during the travel period and 
one month after return. Appropriate use of exposure prophylaxis was defined as patients regularly using impregnated bed net and skin repellent.

Apyrexia (fever clearance) was defined as a tympanic temperature below $37.8^{\circ} \mathrm{C}$ and was monitored at day 3, day 7 and one month. Parasite clearance was defined as a negative thin/thick blood film and was monitored at day 3, day 7 and one month.

Adverse drug reactions (ADR) were reported using a questionnaire administered by the physician. An assessment of patients' perception of tolerance was performed, using the following terms: good, satisfactory, bad, and very bad tolerance. In the same way, assessment of patients' perception of AP efficacy was performed. Patients were asked their subjective feeling about the treatment, using the following items: efficient, moderately, poorly and not efficient in the questionnaire, without clinical or biological data. Data were captured on a standardized datasheet and transmitted to the study principal investigator at the end of follow-up. A limited number of patients were also included in another observational study (the European Malther study) recently published [4].

\section{Data analysis}

Statistical analysis was performed using Stata version 10 software (StataCorp LP, 4905 Lakeway Drive, College Station, TX 77845, USA). Descriptive analyses were comprised of frequency distributions and proportions for each variable category, with their quartiles and confidence intervals (CI) 95\%. Group comparisons were performed using Chi square test and Fisher's exact test for categorical variables. Spearman's rank correlation coefficient was used to assess association between two continuous variables. Logistic regression analysis was performed to measure association between digestive ADR and patient's characteristics as independent variables: sex, age group, country of birth, chronic illness (cardiopathy, obesity, diabetes mellitus, kidney and respiratory diseases, HIV infection), type of chemoprophylaxis, type of travel, parasitaemia at diagnosis and at day 3 nausea at presentation, defined as nausea reported at diagnosis, and immunity, classified in semi-immune person or non immune".

Odds ratios (OR) and 95\% CI were calculated from $\beta$ coefficients and their standard errors. Variables with a $p$-value $<0.30$ were included in the adjusted model.

\section{Results}

\section{Population}

During the study period, 553 patients met eligibility criteria and were enrolled in the study. The median age of patients was 38.3 years old (12-79) and 66\% were male (sex ratio 1.9$)$. The majority of patients $(90.8 \%)$ were born outside Europe, mainly in Africa (88.6\%). Information on co-morbidities was available for 478 (86.4\%): 21 were HIV positive (4\%); and 44 (7.9\%) had a cardiopathy. Nearly half of enrolled patients $(n=264 ; 47.7 \%)$ declared at least one previous onset of malaria.

Countries of contamination were mainly located in Africa, especially West Africa for 342 (61.8\%) travellers. Only three $(0.5 \%)$ and two $(0.4 \%)$ were infected in Asia and the Caribbean Islands, respectively. Most of the patients were migrants who visited friends and relatives (VFR) $(n=431,77.9 \%)$. Others were backpackers $(n=33$, $6.0 \%)$ and tourists resident in hostels $(\mathrm{n}=11,2.2 \%)$.

A pre-travel consultation was reported in 267 travellers $(48.3 \%)$, mostly by their family practitioner (42.3\%). Two-hundred and twenty-two patients (40.1\%) declared having taken malaria chemoprophylaxis (chloroquineproguanil in $64 \%$ of the cases). Information on compliance to chemoprophylaxis was available for 222 subjects and was classified as good for 50 cases (22.5\%). Seventyeight subjects (14.1\%) declared having used exposure prophylaxis, including 12 (2.2\%) with appropriate exposure prophylaxis, i e, regular use of impregnated bed net and skin repellent. Twenty patients (3.6\%) experienced digestive disorders during their stay. There was no relationship between malaria chemoprophylaxis and digestive disorders $(p=0.14)$. Twenty-two patients were treated by intravenous quinine (14 patients for 24 hours or less, four for 48 hours and four for 72 hours) before receiving AP because of vomiting at admission. Table 1 summarizes the main characteristics of patients enrolled.

\section{Diagnosis}

The median time between onset and diagnosis was five days [1-64]. Initial clinical presentation comprised headache (46.3\%), nausea and vomiting (28.2\%), diarrhoea (18.5\%), myalgia (14.7\%), abdominal pain (5.8\%) and arthralgia (3.6\%). For 175 patients (31.6\%), no fever was noted at admission (Table 2).

\section{Biology}

The main data are summarized in Table 3. All patients were infected by $P$. falciparum. In two cases $P$. falciparum was associated with another species: one with Plasmodium vivax from India and one with Plasmodium ovale from Gabon.

Median parasitaemia at diagnosis was $0.52 \%$ of red blood cell (0.01-5.0). Haemoglobin level was under or equal $8 \mathrm{~g} / \mathrm{dL}$ at day 3 for 18 patients (3.9\%) compared to ten $(1.9 \%)$ at diagnosis $\left(p<10^{-3}\right)$. There was no correlation between parasitaemia and haemoglobin level at diagnosis $(r=-0.0017, p=0.97)$. There was no correlation between the time elapsed between symptoms onset and diagnosis on one hand and haemoglobin level at diagnosis or at day 3 on the other hand $\left(r=-0.21, \mathrm{p}<10^{-3}\right.$ and $r=-0.22$, $\mathrm{p}<10^{-3}$, respectively). At admission, platelets count was 
Table 1 Main characteristics of 553 patients treated with atovaquone-proguanil for imported uncomplicated malaria

\begin{tabular}{|c|c|}
\hline $\begin{array}{l}\text { Male: female ratio } \\
\text { Median age in years }\end{array}$ & $\begin{array}{l}1.9 \\
38.3(12-79)\end{array}$ \\
\hline Median weight (kg) & $74(40-109)$ \\
\hline \multicolumn{2}{|l|}{ Continent of birth N (\%) } \\
\hline Europe & $51(9.2)$ \\
\hline French West Indies & $4(0.7)$ \\
\hline Africa & $490(88.6)$ \\
\hline Others & $8(1.5)$ \\
\hline Previous history of malaria & $264 / 492^{*}(53.7)$ \\
\hline HIV positive & $21 / 478^{*}(4.4)$ \\
\hline Pre-travel visit & $267(48.3)$ \\
\hline Travel clinic & $74(27.7)$ \\
\hline Family doctor & $113(42.3)$ \\
\hline Unknown & $80(30.0)$ \\
\hline Chemoprophylaxis & $222(40.1)$ \\
\hline Chloroquine & $30(13.5)$ \\
\hline Chloroquine-proguanil & $142(64)$ \\
\hline Mefloquine & $24(10.8)$ \\
\hline Atovaquone-proguanil & $1(0.4)$ \\
\hline Doxycycline & $13(5.9)$ \\
\hline Proguanil & $10(4.5)$ \\
\hline Unknown & $2(0.9)$ \\
\hline Compliance to chemoprophylaxis & $50 / 222^{*}(22.5)$ \\
\hline \multicolumn{2}{|l|}{ Non-medical prophylaxis } \\
\hline Air-conditionning only & $1(0.2)$ \\
\hline Insecticides only & $5(0.9)$ \\
\hline Unimpregnated bed net only & $11(2)$ \\
\hline Impregnated bed net only & $23(4.1)$ \\
\hline Repellents only & $23(4.1)$ \\
\hline Impregnated bed net and repellents & $12(2.2)$ \\
\hline No prophylaxis & $400(72.4)$ \\
\hline Unknown & $78(14.1)$ \\
\hline \multicolumn{2}{|l|}{ Place of contamination } \\
\hline West Africa & $342(61.8)$ \\
\hline Central Africa & $148(26.8)$ \\
\hline Madagascar and Comoros & $51(9.2)$ \\
\hline East Africa & $5(0.9)$ \\
\hline Asia & $3(0.5)$ \\
\hline Angola and South Africa & $2(0.4)$ \\
\hline Haïti and French Guyana & $2(0.4)$ \\
\hline
\end{tabular}

Table 1 Main characteristics of 553 patients treated with atovaquone-proguanil for imported uncomplicated malaria (Continued)

\begin{tabular}{ll}
\hline Type of travel & \\
Backpackers & $33(6.0)$ \\
Hostel & $11(2.0)$ \\
Visiting friends and relatives & $431(77.9)$ \\
Unknown & $78(14.1)$ \\
\hline$*$ number of patients with available data.
\end{tabular}

Table 2 Admission variables and outcome in $\mathbf{5 5 3}$ patients treated with atovaquone-proguanil for imported uncomplicated malaria

\begin{tabular}{ll}
\hline Temperature at diagnosis $\mathbf{N}(\%)$ & \\
\hline$\leq 37.7 C^{\circ}$ & $175(31.6)$ \\
$37.8-39 C^{\circ}$ & $208(37.6)$ \\
$39.1-40 C^{\circ}$ & $104(18.8)$ \\
$>40 C^{\circ}$ & $19(3.4)$
\end{tabular}

Symptoms at diagnosis

Headache

$256(46.3)$

Nausea/vomiting

$156(28.2)$

Diarrhoea

$102(18.5)$

Myalgia

$81(14.7)$

Abdominal pain

$32(5.8)$

Arthralgia

$20(3.6)$

Compliance to follow-up

Day 3

$469(84.1)$

Day 7

$364(65.8)$

Day 30

$265(47.9)$

Hospitalization

Hospitalized at diagnosis

$191(34.5)$

Still hospitalized at day 3

$124(22.4)$

Still hospitalized at day 7

$15(2.7)$

Still hospitalized at day 30

$2(0.3)$

Fever clearance (apyrexia)

Day 3

$403 / 425^{*}(94.8)$

Day 7

$323 / 323^{*}(100)$

Day 30

$227 / 227^{*}(100)$

Parasitological clearance (negative parasitaemia)

\begin{tabular}{ll} 
Day 3 & $292 / 425^{*}(68.7)$ \\
Day 7 & $331 / 331^{*}(100)$ \\
Day 30 & $215 / 217^{*}(99.1)$ \\
\hline
\end{tabular}

*: number of patients with available data. 
Table 3 Biology data in $\mathbf{5 5 3}$ patients treated with atovaquone-proguanil for imported uncomplicated malaria

\begin{tabular}{|c|c|c|c|c|}
\hline & Diagnosis & Day 3 & Day 7 & Day 30 \\
\hline Haemoglobin $(g / d L)$ & $N(\%)$ & N (\%) & $N(\%)$ & $N(\%)$ \\
\hline$\leq 8$ & $11(1.9)$ & $16(3.4)$ & $4(1.1)$ & 0 \\
\hline $8.1-10$ & $28(5.1)$ & $55(11,7)$ & $48(13.2)$ & $17(6.4)$ \\
\hline $10.1-12$ & $136(24.6)$ & $162(34.6)$ & $126(34.6)$ & $73(27.6)$ \\
\hline$>12$ & $378(68.4)$ & $236(50.3)$ & $186(51,1)$ & $175(66.0)$ \\
\hline \multicolumn{5}{|l|}{ Platelets count (per $\mathrm{mm}^{3}$ ) } \\
\hline$\leq 20,000$ & $8(1.4)$ & $4(0.8)$ & 0 & 0 \\
\hline $20,001-50,000$ & $43(7.8)$ & $14(3.0)$ & $1(0.3)$ & 0 \\
\hline $50,001-100,000$ & $173(31.3)$ & $102(21.8)$ & $1(0.3)$ & 0 \\
\hline $100,001-150,000$ & $160(28.9)$ & $121(25.8)$ & $6(1.6)$ & $7(2,6)$ \\
\hline$>150,000$ & $169(30.6)$ & $228(48.6)$ & $356(97.8)$ & $258(97,4)$ \\
\hline \multicolumn{5}{|l|}{ Leucocytosis } \\
\hline White blood cells $\leq 4,500$ per $\mathrm{mm}^{3}$ & $218(39.4)$ & $242(51.6)$ & $55(15.1)$ & $48(18.1)$ \\
\hline White blood cells $>4,500$ per $\mathrm{mm}^{3}$ & $335(60.6)$ & $227(48.4)$ & $309(84.9)$ & $217(81.9)$ \\
\hline \multicolumn{5}{|l|}{ Cytolysis } \\
\hline ALAT $\leq 1 \mathrm{~N}$ & $385(69.6)$ & $287(61.2)$ & $201(55.2)$ & 219 (82.6) \\
\hline ALAT $1.1-2 \mathrm{~N}$ & $135(24.4)$ & $140(29.9)$ & $117(32.1)$ & $44(16.6)$ \\
\hline ALAT $2.1-3 \mathrm{~N}$ & $27(4.9)$ & $24(5.1)$ & $20(5.5)$ & $2(0.8)$ \\
\hline ALAT $>3 \mathrm{~N}$ & $6(1.1)$ & $18(3.8)$ & $26(7.1)$ & 0 \\
\hline \multicolumn{5}{|l|}{ Creatinine $(\mu \mathrm{mol} / \mathrm{L})$} \\
\hline$\leq 120$ & $507(91.7)$ & $431(91.9)$ & $349(95.9)$ & $4(1.5)$ \\
\hline $121-140$ & $36(6.5)$ & $25(5.3)$ & $8(2.2)$ & $253(95.5)$ \\
\hline$>140$ & $10(1.8)$ & $13(2.8)$ & $7(1.9)$ & $8(3.0)$ \\
\hline
\end{tabular}

normal $\left(>150,000 / \mathrm{mm}^{3}\right)$ in $30.6 \%$ of cases and less than $20,000 / \mathrm{mm}^{3}$ in eight patients $(1.5 \%)$. At day $7,99.4 \%$ of patients had more than 100,000 platelets $/ \mathrm{mm}^{3}$.

\section{Outcome}

Follow-up was the following: 469 patients (85\%) at day 3,364 at day $7(66 \%)$ and 265 patients (48\%) completed the study one month after diagnosis. About one third of patients were hospitalized $(\mathrm{n}=191,34.5 \%)$. At day 3, 124 (22.4\%) were still hospitalized and $15(2.7 \%)$ at day 7 . At one month, two patients were hospitalized: the first one was re-hospitalized for a relapse; the second one definitely cleared his parasitaemia at day 3 but was still hospitalized at day 30 for an HIV-related complication.

Fever clearance was obtained at day 3 in $95 \%$ of cases (403 of 425 for which information were available) and for all patients at day 7 (Table 2). All patients at one month were apyretic. Negative parasitaemia was observed in $68.7 \%$ of patients at day 3 and for all patients at day 7. Treatment failure was observed in three patients: two relapsed at day 30 and one at day 23. During follow up, these three patients did not return to an endemic area. All were successfully treated by mefloquine. Perceived efficacy amongst the 419 patients who answered was classified as efficient for 305 (72.8\%), moderately for $101(24.1 \%)$, poor for eight (1.9\%) and not efficient for five (1.2\%).

\section{Adverse drug reactions and drug switch}

A total of 177 adverse drug reactions (ADR) attributed to AP were reported by the patients during the follow-up. Most of them were reported at day $3(n=150)$ and were digestive ( $n=115,77 \%$ of all ADR reported at day 3$)$ : most of them consisted of nausea and vomiting followed by headache and skin disorders (Table 4).

In the multivariate analysis, when adjusted to origin, type of travel and parasitaemia at diagnosis, backpackers were more likely to experiment digestive ADR at day 3 than VFR (OR = 3.8 CI 95\% [1.8-8.2]) (Table 5).

Assessment of tolerance by patients for the 437 who answered to the questionnaire was classified as good for 304 (69.6\%), satisfactory for 116 (23.8\%), bad for 41 (8.4\%) and very bad for 27 (5.5\%). In 20 cases, a switch to another drug was reported mainly because of vomiting $(n=15$, $75 \%)$, confusion $(n=2,10 \%)$, headache $(n=1,5 \%)$, cutaneous eruption $(n=1,5 \%)$, and suspected resistance because of a positive smear at day $3(n=1,5 \%)$. 


\begin{tabular}{|c|c|}
\hline At Day $3(\mathrm{~N}=469(\%))$ & n (\%) \\
\hline Digestive adverse reactions & $115(24.5$ \\
\hline Nausea or vomiting & $82(17.5)$ \\
\hline Diarrhoea & $16(3.4)$ \\
\hline Abdominal pain & $10(2.1)$ \\
\hline Others & $7(1.5)$ \\
\hline Cutaneous & $10(2.1)$ \\
\hline Headache & $18(7.4)$ \\
\hline Myalgia & $3(0.6)$ \\
\hline Arthralgia & $3(0.6)$ \\
\hline Anxiety & $1(0.2)$ \\
\hline Total ADR ${ }^{\circ}$ at Day 3 & $150(32.0$ \\
\hline \multicolumn{2}{|l|}{ At Day $7(\mathrm{~N}=364(\%))^{*}$} \\
\hline Digestive adverse reactions & $11(3.0)$ \\
\hline Nausea & $3(0.8)$ \\
\hline Diarrhoea & $4(1.1)$ \\
\hline Others & $4(1.1)$ \\
\hline Cutaneous & $7(1.9)$ \\
\hline Headache & $7(1.9)$ \\
\hline Total ADR ${ }^{\circ}$ at Day 7 & $25(6.9)$ \\
\hline \multicolumn{2}{|l|}{ At Day $30(\mathrm{~N}=265(\%))^{*}$} \\
\hline Digestive adverse reactions & $1(0.4)$ \\
\hline Nausea & 0 \\
\hline Diarrhoea & $1(0.4)$ \\
\hline Cutaneous & $1(0.4)$ \\
\hline Headache & 0 \\
\hline Total ADR* at Day $30^{\circ}$ & $2(0.8)$ \\
\hline
\end{tabular}

*: Differences between denominators are due to patients lost to follow up. ADR: Adverse drugs reactions.

\section{Discussion}

This 'real life condition' prospective, observational study of 553 patients treated by AP for uncomplicated P. falciparum malaria seems to be the largest series assessing the use of AP in the field of imported malaria. Patient profile (mostly young male adults of African origin living in Europe and infected in West Africa) are similar to those observed in the majority of studies on imported malaria [18-24,26-28]. The high percentage of HIV-infected patients (4.4\%) observed in the study may be explained by the fact that the majority of patients are of African origin and because the nine recruiting centres are travel clinics linked to infectious diseases departments where a majority of the HIV patients living in Paris area are followed.

Not surprisingly, the rate of chemoprophylaxis and exposure prophylaxis was low. Clinical and biological presentation had no specificity but it is of interest to note that nearly one third of patients had no fever at admission, which might be misleading for non-experienced practitioners. Compared to some other studies describing non-comparative cohorts of malaria patients, followup, even too low, might be considered satisfactory given such a 'real life' design for this cohort, since outcome data are available for the majority at day 3 and since nearly half of patients were seen one month after treatment [16,19-21,26-29]. By contrast the loss to follow-up rate at one month in the recent European study was much lower, at $25 \%$ [4].

With regard to efficacy, if a majority of patients (95\%) were fever-free at day 3 , nearly a third of them were still parasitaemic confirming that AP is slow-acting $[15,16,19$, 20,30,31]. The analysis of efficacy in a per-protocol approach gives a cure rate of $99 \%$ (three relapses of 265 patients with a follow-up at one month) which is comparable to other treatments $[15,16,22,32,33]$. Details on relapses were available for only two cases. In both cases the reason was probably suboptimal plasmatic AP level: consecutive to obesity $(115 \mathrm{~kg})$ in one case and to a poor absorption in the second case, since the patient had not taken food with the drug [34]. As a consequence, physicians should re-assess AP dosage in obese patients and should insist on food intake with AP to optimize its absorption.

Even though rare under AP and comparable to other malaria treatment ( $1 \%$ in this study's series), the risk of relapse has to be considered by physicians given the potential severe outcome at a time when the diagnosis of malaria may be omitted (long delay after travel in endemic area) $[4,21,23]$. Given that relapses occur usually between day 14 and day 30 (and in a few cases later) after treatment, physicians should organize a 'recapture' system for patients lost to follow-up after day 7, even limited to a phone call, in order to identify promptly a possible recrudescence $[4,35]$.

Perceived efficacy of AP was satisfying. This evaluation is not as valid as parasitological efficacy but it has not been studied in Africa before, both for curative treatment and for prophylaxis in travellers. It is considered as a significant predictor for compliance to treatment and preventative behaviours [36,37].

With regard to tolerance of AP, data of this study highlighted a high rate of digestive ADR, mainly at day 3, especially nausea and vomiting. Digestive ADR represented $77 \%$ of ADR reported at day 3 and $72 \%$ of the totality of ADR reported during follow-up. It seems that digestive ADR were more frequent in backpackers compared to migrants, with no particular explanation, and no comparable data were found in the literature. In $18 \%$ of cases $(n=15)$, vomiting was severe enough to justify a change to second-line treatment. This high occurrence of digestive ADR could be partially explained by the population enrolled in the study since black people are known to 
Table 5 Digestive adverse drug reactions under atovaquone-proguanil

\begin{tabular}{|c|c|c|c|c|c|c|c|c|c|c|}
\hline \multirow{3}{*}{ Sex } & & \multirow{3}{*}{$\begin{array}{l}\text { Number } \\
306\end{array}$} & \multicolumn{2}{|c|}{ Digestive ADR day 3} & \multicolumn{2}{|c|}{ Crude OR } & \multirow{3}{*}{$\begin{array}{l}p \\
0.82\end{array}$} & \multicolumn{2}{|c|}{ Adjusted OR } & \multirow[t]{2}{*}{$p$} \\
\hline & & & \multirow{2}{*}{$\begin{array}{l}\mathbf{N} \\
74\end{array}$} & \multirow{2}{*}{$\frac{\mathbf{( \% )}}{(24.2)}$} & \multirow[b]{2}{*}{1} & & & & & \\
\hline & Male & & & & & & & & & \\
\hline & Female & 163 & 41 & $(25.1)$ & 0.9 & {$[0.6-1.4]$} & & & & \\
\hline \multirow[t]{4}{*}{ Age } & $\leq 30$ & 131 & 39 & $(29.8)$ & 1 & & 0.36 & & & \\
\hline & $31-40$ & 129 & 27 & $(20.9)$ & 0.6 & {$[0.3-1.1]$} & & & & \\
\hline & $41-50$ & 121 & 30 & $(24.8)$ & 0,8 & {$[0.4-1.3]$} & & & & \\
\hline & $>50$ & 88 & 19 & $(21.6)$ & 0.6 & {$[0.3-1.2]$} & & & & \\
\hline \multirow[t]{3}{*}{ Origin } & African & 415 & 92 & $(22.2)$ & 1 & & $<0.01$ & 1 & & 0.19 \\
\hline & European & 43 & 16 & $(37.2)$ & 2.1 & {$[1.0-4.0]$} & & 1.2 & {$[0.5-2.8]$} & \\
\hline & Others & 11 & 7 & $(63.6)$ & 6.1 & {$[1.7-21.4]$} & & 3.5 & {$[0.9-14.0]$} & \\
\hline \multirow[t]{2}{*}{ Immunity } & Non immune & 233 & 60 & $(25.7)$ & 1 & & 0.54 & & & \\
\hline & Semi-immune & 236 & 55 & $(23.3)$ & 0.88 & $6-1.3]$ & & & & \\
\hline \multirow[t]{2}{*}{ Nausea at presentation } & No & 329 & 82 & $(24.9)$ & 1 & & 0.76 & & & \\
\hline & Yes & 140 & 33 & $(23.6)$ & 0.93 & $.58-1.48]$ & & & & \\
\hline \multirow[t]{2}{*}{ Chronic illness } & No & 425 & 105 & $(24.7)$ & 1 & & 0.77 & & & \\
\hline & Yes & 44 & 10 & $(22.7)$ & 0,9 & {$[0.4-1.9]$} & & & & \\
\hline \multirow[t]{2}{*}{ Chemoprohylaxis } & No & 192 & 50 & $(26.0)$ & 1 & & 0.51 & & & \\
\hline & Yes & 277 & 65 & $(23.5)$ & 0.9 & {$[0.6-1.3]$} & & & & \\
\hline \multirow[t]{4}{*}{ Type of travel } & $V F R^{*}$ & 378 & 80 & $(21.2)$ & 1 & & $<0.01$ & 1 & & $<0.01$ \\
\hline & Hostel & 10 & 4 & $(40.0)$ & 2.5 & {$[0.7-9.0]$} & & 2.8 & {$[0.8-10.4]$} & \\
\hline & Backpackers & 30 & 15 & $(50.0)$ & 3.7 & {$[1.7-7.9]$} & & 3.8 & {$[1.8-8.2]$} & \\
\hline & Unknown & 51 & 16 & (31.4) & 1.7 & {$[0.9-3.2]$} & & 1.7 & {$[0.9-3.9]$} & \\
\hline \multirow[t]{5}{*}{ Parasitaemia at diagnosis } & $\leq 0.10 \%$ & 144 & 27 & $(18.7)$ & 1 & & 0.29 & 1 & & 0.26 \\
\hline & $0.11-0.50 \%$ & 148 & 42 & $(28.4)$ & 1.7 & {$[1.0-3.0]$} & & 1.8 & {$[1.0-3.1]$} & \\
\hline & $0.51-1.00 \%$ & 52 & 11 & $(21.2)$ & 1.2 & {$[0.5-2.5]$} & & 1.3 & {$[0.6-2.9]$} & \\
\hline & $>1 \%$ & 90 & 25 & $(22.8)$ & 1.7 & {$[0.9-3.1]$} & & 1.9 & {$[1.0-3.5]$} & \\
\hline & Unknown & 35 & 10 & $(28.6)$ & 1.7 & {$[0.7-4.0]$} & & 1.8 & {$[0.7-4.2]$} & \\
\hline \multirow[t]{3}{*}{ Parasitaemia at day 3} & Negative & 290 & 72 & $(24.8)$ & 1 & & 0.97 & & & \\
\hline & Positive & 128 & 31 & $(24.2)$ & 0.9 & {$[0.6-1.6]$} & & & & \\
\hline & Unknown & 51 & 12 & $(23.5)$ & 0.9 & {$[0.5-1.9]$} & & & & \\
\hline
\end{tabular}

*Visiting friends and relatives.

have a lower clearance rate of atovaquone compared to white people [38]. Yet there were no relationship between immunity, or African origin, with digestive ADR.

Surprisingly, these digestive side effects are one of the most important from studies. A review of ten trials comparing Atovaquone-Proguanil (AP) with other anti-malarial drugs for uncomplicated malaria report a median rate of nausea and/or vomiting (inter quartile range) of $15.6 \%$ (5.2 - 25.0) for Atovaquone-Proguanil whereas other studies did not report this ADR [10,11,15,16,18,20,30,31,39]. To discriminate digestive ADR from symptoms related to malaria is difficult in a cohort and only clinical trials would be able to make the distinction. This study didn't compare AP to other drugs, and this misclassification could be a bias.
Nausea at diagnosis was not associated with digestive ADR at day 3, which involves AP rather than acute malaria in the etiology of these adverse effects.

Nevertheless, data from this series on digestive ADR are comparable to the results of a recent cohort study showing a higher switch rate to second-line treatment in patients treated with AP, compared to others [4].

The design of this study does not enable to guide physicians on their choice of anti-malarial drug. However, the significant risk of vomiting associated with AP needs to be taken into account, especially in patients already complaining of nausea and vomiting at the time of diagnosis. The need for fat intake with AP, as is recommended to improve absorption, may be an additional 
risk factor for vomiting [38]. Prescription of metoclopramide is probably not a solution since it decreases the bioavailability of atovaquone [40].

As observed in the literature, this study did not reveal any liver toxicity. Moderate variations in transaminase level observed at day 3 and 7 were not significant and were possibly due to malaria parasite itself $[12,14,30,41]$.

A drop in haemoglobin level, as observed here, was commonly reported after initiation of treatment of acute malaria due to malaria haemolysis [42]. The absence of correlation between haemoglobin at diagnosis and initial parasitaemia is in line with other studies [43].

In 2007, French experts' consensus recommended both AP and artemether-lumefantrine as first-line treatment for acute uncomplicated malaria [5]. As a consequence and because artemether-lumefantrine, even if registered throughout Europe in 1999, is only available since 2007 in France, the use of AP has progressively increased from $25 \%$ in 2006 to $46 \%$ in 2011 [3]. On the one hand, AP's good efficacy was confirmed by this series while its limitations were described (mainly slow-acting drug, poor absorption, and ADR, such as vomiting). On the other hand, use of artemether-lumefantrine in the particular situation of imported malaria still has a limited experience. Hence, regarding imported malaria, the question of which association between AP or artemisinin combination therapy (ACT) is the best option remains. A clinical trial is currently comparing the use of AP and ACT in the indication of uncomplicated malaria in nonendemic areas and will hopefully bring the answer [44].

With the introduction of ACT in Europe (artemetherlumefantrine and, since mid-2012, dihydroartemisininpiperaquine are both authorized in France and in a limited number of European countries) for uncomplicated acute malaria onset, the use of AP will probably decrease in favour of ACT, due to its prompt efficacy and good tolerance.

\section{Conclusion}

This observational series of 553 cases, the largest to date in number of patients, describes a large experience in using AP for imported uncomplicated malaria in real life conditions. Despite a non-comparative design, it appears that its efficacy is good and comparable to other similar drugs. The study confirms that AP is a valuable treatment option, while ADR, such as vomiting and its limited absorption in some cases, may be a limitation for its use.

\section{Competing interests}

The authors have declared that they have no competing interests.

\section{Authors' contributions}

HC, PR and OB participated in the design of the study and performed the statistical analysis. PR and OB conceived of the study, and participated in its coordination. HC, JC, SM and OB contributed to the draft manuscript. OF, PB,
PC, HG, PHC, NG and MB participated in the recruitment of included patients. All authors read and approved the final manuscript.

\section{Author details}

'Department of Infectious and Tropical Diseases, Hôpital Avicenne, Assistance Publique-Hôpitaux de Paris, Bobigny, France. ²LES EA3412, Université Paris 13 - Sorbonne Paris Cité, Paris, France. ${ }^{3}$ Department of Infectious and Tropical Diseases, Hôpital Bichat, Assistance Publique-Hôpitaux de Paris, Paris, France. ${ }^{4}$ Department of Internal Medicine, Hôpital Louis Mourrier, Assistance Publique - Hôpitaux de Paris, Colombes, France. ${ }^{5}$ Department of Parasitology, Hôpital Delafontaine, Saint Denis, France. Institut Pasteur, Centre Médical, Paris, France. 'Department of Internal Medicine, Hôpital Robert Ballanger, Aulnay-Sous-Bois, France. ${ }^{8}$ Department of Infectious and Tropical Diseases, Hôpital Saint Antoine, Assistance Publique - Hôpitaux de Paris, Paris, France. ${ }^{9}$ Department of Parasitology, Hôpital Bicètre, Assistance Publique - Hôpitaux de Paris, Paris, France. ${ }^{10}$ Department of Internal Medicine, Hôpital Jean verdier, Assistance Publique - Hôpitaux de Paris, Paris, France.

Received: 4 September 2013 Accepted: 30 October 2013 Published: 7 November 2013

\section{References}

1. WHO: World malaria report 2010. Geneva: World Health Organization; 2010.

2. World Health Organization Regional Office for Europe: Centralized information system for infectious diseases (CISID).

3. French Institute of Public Health, InVS: French national reference centre for malaria - Report 2011. Saint-Maurice, France: French Institute of Public Health, InVS; 2012:79.

4. Bouchaud O, Muehlberger N, Parola P, Calleri G, Matteelli A, Peyerl-Hoffmann G, Mechaï F, Gautret P, Clerinx J, Kremsner PG, Jelinek T, Kaiser A, Beltrame A, Schmid M, Kern P, Probst M, Bartoloni A, Weinke T, Grobusch MP: Therapy of uncomplicated falciparum malaria in Europe: MALTHER - a prospective observational multicentre study. Malar J 2012, 11:212.

5. Société de Pathologie Infectieuse de Langue Française: Management and prevention of imported Plasmodium falciparum malaria (Revision 2007 of the 1999 Consensus Conference) (in French). Med Mal Infect 2008, 38:68-117.

6. Hudson AT: Lapinone, menoctone, hydroxynaphtoquinones and similar structures. In Handbook of experimental pharmacology, antimalarial drugs. Edited by Peters WRW. Berlin - Heidelberg: Springer Verlag; 1984:343-361.

7. Hudson AT, Randall AW, Fry M, Ginger CD, Hill B, Latter VS, McHardy N, Williams RB: Novel anti-malarial hydroxynaphthoquinones with potent broad spectrum anti-protozoal activity. Parasitology 1985, 90:45-55.

8. Gutteridge WE: Chemotherapy. In Modern parasitology. Edited by FG C. Oxford: Blackwell Scientific Publications; 1993:218-239.

9. Chiodini PL, Conlon CP, Hutchinson DB, Farquhar JA, Hall AP, Peto TE, Birley $\mathrm{H}$, Warrell DA: Evaluation of atovaquone in the treatment of patients with uncomplicated Plasmodium falciparum malaria. J Antimicrob Chemother 1995, 36:1073-1078.

10. Bustos DG, Canfield CJ, Canete-Miguel E, Hutchinson DB: Atovaquone-proguanil compared with chloroquine and chloroquine-sulfadoxine-pyrimethamine for treatment of acute Plasmodium falciparum malaria in the Philippines. I Infect Dis 1999, 179:1587-1590.

11. De Alencar FE, Cerutti C, Durlacher RR, Boulos M, Alves FP, Milhous W, Pang LW: Atovaquone and proguanil for the treatment of malaria in Brazil. J Infect Dis 1997, 175:1544-1547.

12. Looareesuwan S, Wilairatana P, Chalermarut K, Rattanapong Y, Canfield CJ, Hutchinson DB: Efficacy and safety of atovaquone/proguanil compared with mefloquine for treatment of acute Plasmodium falciparum malaria in Thailand. Am J Trop Med Hyg 1999, 60:526-532.

13. Mulenga M, Sukwa TY, Canfield CJ, Hutchinson DB: Atovaquone and proguanil versus pyrimethamine/sulfadoxine for the treatment of acute falciparum malaria in Zambia. Clin Ther 1999, 21:841-852.

14. Radloff PD, Philipps J, Nkeyi M, Hutchinson D, Kremsner PG: Atovaquone and proguanil for Plasmodium falciparum malaria. Lancet 1996, 347:1511-1514.

15. Bouchaud O, Monlun E, Muanza K, Fontanet A, Scott T, Goetschel A, Chulay JD, Le Bras J, Danis M, Le Bras M, Coulaud JP, Gentilini M: Atovaquone plus proguanil versus halofantrine for the treatment of imported acute uncomplicated Plasmodium falciparum malaria in 
non-immune adults: a randomized comparative trial. Am J Trop Med Hyg 2000, 63:274-279.

16. Hitani A, Nakamura T, Ohtomo H, Nawa Y, Kimura M: Efficacy and safety of atovaquone-proguanil compared with mefloquine in the treatment of nonimmune patients with uncomplicated $P$. falciparum malaria in Japan. $J$. Infect Chemother 2006, 12:277-282.

17. Van Agtmael M, Bouchaud O, Malvy D, Delmont J, Danis M, Barette S, Gras C, Bernard J, Touze JE, Gathmann I, Mull R: The comparative efficacy and tolerability of CGP 56697 (artemether + lumefantrine) versus halofantrine in the treatment of uncomplicated falciparum malaria in travellers returning from the Tropics to The Netherlands and France. Int J Antimicrob Agents 1999, 12:159-169.

18. Malvy D, Djossou F, Vatan R, Pistone T, Etienne G, Longy-Boursier M, Le Bras M: [Experience with the combination atovaquone-proguanil in the treatment of uncomplicated Plasmodium falciparum malaria-report of 112 cases] (in French). Med Trop (Mars) 2002, 62:229-231.

19. Thybo S, Gjorup I, Ronn AM, Meyrowitsch D, Bygberg IC: Atovaquoneproguanil (malarone): an effective treatment for uncomplicated Plasmodium falciparum malaria in travelers from Denmark. J Travel Med 2004, 11:220-223.

20. Vatan $R$, Pistone $T$, Millet $P$, Etienne $G$, Mercié $P$, Longy-Boursier M, Malvy D: [Retrospective analysis of 107 imported adult cases of malaria: experience report of uncomplicated falciparum malaria treatment in adults with oral atovaquone-proguanil] (in French). Presse Med 2006, 35:571-577.

21. Bottieau E, Clerinx J, Colebunders R, Van den Enden E, Wouters R, Demey H, Van Esbroeck M, Vervoort T, Van Gompel A, Van den Ende J: Selective ambulatory management of imported falciparum malaria: a 5-year prospective study. Eur J Clin Microbiol Infect Dis 2007, 26:181-188.

22. Parola P, Minodier P, Soula G, Jaffré Y, Badiaga S, Retornaz K, Garnier JM, Delmont J, Parzy D, Brouqui P: [Imported malaria at the Marseilles Hôpital-Nord, France: a prospective study on 352 cases between 2001 and 2003] (in French). Med Mal Infect 2005, 35:482-488.

23. Ranque $S$, Marchou B, Malvy D, Adehossi E, Laganier R, Tissot-Dupont $H$, Lotte A, Dydymsky S, Durant J, Stahl JP, Bosseray A, Gaillat J, Sotto A, Cazorla C, Ragneau JM, Brouqui P, Delmont J: Treatment of imported malaria in adults: a multicentre study in France. QJM 2005, 98:737-743.

24. Pistone T, Diallo A, Receveur MC, Mansour R, Roger-Schmeltz J, Millet P, Malvy D: [Imported malaria in University Hospital Center of Bordeaux, France, 2000-2007: a comparison study with the French national epidemiological data] (in French). Bull Soc Pathol Exot 2010, 103:104-110.

25. Reyburn H: New WHO guidelines for the treatment of malaria. BMJ 2010 340:c2637.

26. Jelinek T, Schulte C, Behrens R, Grobusch MP, Coulaud JP, Bisoffi Z, Matteelli A Clerinx J, Corachán M, Puente S, Gjørup I, Harms G, Kollaritsch H, Kotlowski A, Björkmann A, Delmont JP, Knobloch J, Nielsen LN, Cuadros J, Hatz C, Beran J, Schmid ML, Schulze M, Lopez-Velez R, Fleischer K, Kapaun A, McWhinney P, Kern P, Atougia J, Fry G, Da Cunha S, Boecken G: Imported Falciparum malaria in Europe: sentinel surveillance data from the European network on surveillance of imported infectious diseases. Clin Infect Dis 2002, 34:572-576.

27. D'Acremont $V$, Landry P, Darioli R, Stuerchler D, Pécoud A, Genton B: Treatment of imported malaria in an ambulatory setting: prospective study. BMJ 2002, 324:875-877.

28. Kockaerts $Y$, Vanhees S, Knockaert DC, Verhaegen J, Lontie M, Peetermans WE: Imported malaria in the 1990s: a review of 101 patients. Eur J Emerg Med 2001, 8:287-290.

29. Hatz C, Soto J, Nothdurft HD, Zoller T, Weitzel T, Loutan L, Bricaire F, Gay F, Burchard G-D, Andriano K, Lefèvre G, De Palacios PI, Genton B: Treatment of acute uncomplicated falciparum malaria with artemether-lumefantrine in nonimmune populations: a safety, efficacy, and pharmacokinetic study. Am J Trop Med Hyg 2008, 78:241-247.

30. Osei-Akoto A, Orton L, Owusu-Ofori SP: Atovaquone-proguanil for treating uncomplicated malaria. Cochrane Database Syst Rev 2005, 19(4):CD004529.

31. Giao PT, De Vries PJ, Hung LQ, Binh TQ, Nam NV, Kager PA: CV8, a new combination of dihydroartemisinin, piperaquine, trimethoprim and primaquine, compared with atovaquone-proguanil against falciparum malaria in Vietnam. Trop Med Int Health 2004, 9:209-216.

32. Makanga M, Krudsood S: The clinical efficacy of artemether/lumefantrine (Coartem). Malar J 2009, 8(1):S5.

33. Parola P, Ranque S, Badiaga S, Niang M, Blin O, Charbit JJ, Delmont J, Brouqui P: Controlled trial of 3-day quinine-clindamycin treatment versus 7-day quinine treatment for adult travelers with uncomplicated falciparum malaria imported from the tropics. Antimicrob Agents Chemother 2001, 45:932-935.

34. Durand R, Prendki V, Cailhol J, Hubert V, Ralaimazava P, Massias L, Bouchaud O, Le Bras J: Plasmodium falciparum malaria and atovaquone-proguanil treatment failure. Emerg Infect Dis 2008, 14:320-322.

35. Miura T, Kimura M, Koibuchi T, Endo T, Nakamura H, Odawara T, Wataya Y, Nakamura T, Iwamoto A: Clinical characteristics of imported malaria in Japan: analysis at a referral hospital. Am J Trop Med Hyg 2005, 73:599-603.

36. Hartjes LB, Baumann LC, Henriques JB: Travel health risk perceptions and prevention behaviors of US study abroad students. J Travel Med 2009, 16:338-343.

37. Rutebemberwa E, Nsabagasani X, Pariyo G, Tomson G, Peterson S, Kallander K Use of drugs, perceived drug efficacy and preferred providers for febrile children: implications for home management of fever. Malar J 2009, 8:131.

38. Hussein Z, Eaves J, Hutchinson DB, Canfield CJ: Population pharmacokinetics of atovaquone in patients with acute malaria caused by Plasmodium falciparum. Clin Pharmacol Ther 1997, 61:518-530.

39. Looareesuwan S, Chulay JD, Canfield CJ, Hutchinson DB: Malarone (atovaquone and proguanil hydrochloride): a review of its clinical development for treatment of malaria: malarone clinical trials study group. Am J Trop Med Hyg 1999, 60:533-541.

40. McKeage K, Scott L: Atovaquone/proguanil: a review of its use for the prophylaxis of Plasmodium falciparum malaria. Drugs 2003, 63:597-623.

41. Boggild AK, Parise ME, Lewis LS, Kain KC: Atovaquone-proguanil: report from the CDC expert meeting on malaria chemoprophylaxis (II). Am J Trop Med Hyg 2007, 76:208-223.

42. Menendez C, Fleming AF, Alonso PL: Malaria-related Anaemia. Parasitol Today 2000, 16:469-476

43. Price RN, Simpson JA, Nosten F, Luxemburger C, Hkirjaroen L, Ter Kuile F, Chongsuphajaisiddhi T, White NJ: Factors contributing to anemia after uncomplicated falciparum malaria. Am J Trop Med Hyg 2001, 65:614-622.

44. Evaluation of the riamet ${ }^{\oplus}$ versus malarone ${ }^{\circledast}$ in the treatment of uncomplicated malaria - full text view - clinicaltrials.gov. http://clinicaltrials.gov/ct2/show/ NCT01150344

\section{doi:10.1186/1475-2875-12-399}

Cite this article as: Cordel et al:: Atovaquone-proguanil in the treatment of imported uncomplicated Plasmodium falciparum malaria: a prospective observational study of 553 cases. Malaria Journal 2013 12:399

\section{Submit your next manuscript to BioMed Central and take full advantage of:}

- Convenient online submission

- Thorough peer review

- No space constraints or color figure charges

- Immediate publication on acceptance

- Inclusion in PubMed, CAS, Scopus and Google Scholar

- Research which is freely available for redistribution 